\title{
Human epididymis protein 4 reference limits and natural variation in a Nordic reference population
}

\author{
Nils Bolstad • Miriam Øijordsbakken • Kjell Nustad • \\ Johan Bjerner
}

Received: 30 August 2011 / Accepted: 25 October 2011 / Published online: 22 November 2011

(C) The Author(s) 2011. This article is published with open access at Springerlink.com

\begin{abstract}
The objectives of this study are to establish reference limits for human epididymis protein 4, HE4, and investigate factors influencing HE4 levels in healthy subjects. HE4 was measured in 1,591 samples from the Nordic Reference Interval Project Bio-bank and Database biobank, using the manual HE4 EIA (Fujirebio) for 802 samples and the Architect HE4 (Abbott) for 792 samples. Reference limits were calculated using the statistical software R. The influence of donor characteristics such as age, sex, body mass index, smoking habits, and creatinine on HE4 levels was investigated using a multivariate model. The study showed that age is the main determinant of HE4 in healthy subjects, corresponding to $2 \%$ higher HE4 levels at 30 years (compared to 20 years), $9 \%$ at 40 years, $20 \%$ at 50 years, $37 \%$ at 60 years, $63 \%$ at 70 years, and $101 \%$ at 80 years. HE4 levels are $29 \%$ higher in smokers than in nonsmokers. In conclusion, HE4 levels in healthy subjects are associated with age and smoking status. Age-dependent reference limits are suggested.
\end{abstract}

Keywords Human epididymis protein $4 \cdot \mathrm{HE} 4 \cdot$ Reference values $\cdot$ Epithelial cancer of the ovary

Electronic supplementary material The online version of this article (doi:10.1007/s13277-011-0256-4) contains supplementary material, which is available to authorized users.

\footnotetext{
N. Bolstad $(\bowtie) \cdot$ M. Øijordsbakken $\cdot$ K. Nustad

Department of Medical Biochemistry,

Oslo University Hospital, Radiumhospitalet,

0310 Oslo, Norway

e-mail: Nils.Bolstad@ous-hf.no

J. Bjerner

Fürst Medical Laboratory,

Oslo, Norway
}

\author{
Abbreviations \\ HE4 Human epididymis protein 4 \\ CA125 Cancer antigen 125 \\ RMI Risk of Malignancy Index \\ ROMA Risk of Ovarian Malignancy Algorithm
}

\section{Introduction}

Ovarian cysts and tumors are commonly diagnosed in gynecologic specialist centers. In most instances, particularly in premenopausal women, these cysts and tumors are benign and represent no threat to the health and well-being of the patient [1]. However, the prognosis of malignant ovarian tumors is generally poor, and ovarian cancer remains the leading cause of death from gynecological cancer in developed countries [2]. Several studies have shown that primary treatment by gynecologic oncologists specializing in the treatment of ovarian cancer provides a survival benefit in women with ovarian cancer [3-7], heralding the need for efficient and accurate triage of patients with adnexal masses to appropriate treatment centers.

In developed countries, more than $90 \%$ of ovarian cancers are of epithelial origin. The serum tumor marker cancer antigen 125 (CA125) is often elevated at the time of diagnosis in patients having epithelial ovarian cancer (EOC) $[8,9]$, and CA125 levels have been incorporated in triage algorithms such as the Risk of Malignancy Index (RMI) [10, 11].

Unfortunately, CA125 has important limitations as a diagnostic tool. Sensitivity in stage 1 disease is less than $50 \%$, and in some histological subtypes of EOC, such as mucinous ovarian cancer, CA125 is only rarely elevated $[12,13]$. In terms of specificity, CA125 levels are highly 
volatile in healthy subjects, particularly in premenopausal women. Elevated levels are commonly observed in a broad range of benign conditions, such as endometriosis and pregnancy, and in several non-ovarian malignancies, efficiently thwarting any ambitions of using the marker as a screening tool for ovarian cancer [14]. Because of the limitations of CA125, and the potential clinical utility of efficient serum markers, the search for new tumor markers for ovarian cancer continues. This pursuit has produced an impressive number of scientific publications [15], but has of yet not altered the approach to the patient with an adnexal mass.

Human epididymis protein 4, HE4, has recently been identified as a potential serum tumor marker for ovarian cancer, used alone or in combination with CA125 [16-19]. An algorithm combining HE4, CA125, and menopausal status, the Risk of Ovarian Malignancy Algorithm (ROMA), has thus been shown to improve triage of patients with pelvic tumors compared to CA125 alone and RMI [20-22]. Although some recent studies have questioned the predictive value of the ROMA algorithm [23, 24], there seems to be a surge in the clinical use of HE4, either on its own or in combination with other diagnostics. Finally, preliminary reports suggest that HE4 may be of diagnostic or prognostic value in other malignancies [25-27], but further studies are probably warranted.

With any clinical test, and particularly new tumor markers, it is important to determine its intra- and interindividual biological variation in a reference population. Data are already available concerning HE4 levels in patients with benign conditions and patients with nonovarian malignancies, warranting optimism on behalf of HE4 as a tumor marker [16, 28]. However, the information about HE4 levels in the general population is still very limited. One large study suggesting reference ranges in a female Asian population aged 20-65 has recently been published [29], but the lack of serum donor characteristics somewhat limits the value of this study. In addition, knowing that a significant proportion of women diagnosed with ovarian cancer are of advanced age, we question the appropriateness of completely omitting donors above 65 years of age in a study of this nature.

In the current study, we measured HE4 in 1,591 serum samples from the Nordic Reference Interval Project Bio-bank and Database (NOBIDA) biobank [30] from donors aged 18-86 of both sexes. The study focus is bifold; first, we want to study the relationship between HE4 levels and donor characteristics, such as age, sex, body mass index, creatinine levels, smoking, fasting, and sampling time, and second, we want to establish appropriate reference levels for HE4. We had access to extensive data on the donors, including age, sex, body mass index, a range of biochemical parameters, and smoking status, providing us with the means to identify factors possibly affecting HE4 levels in presumably healthy individuals.

\section{Materials and methods}

\section{Reference samples}

We obtained serum samples from the NOBIDA biobank. Samples were partially stratified to provide a uniform age distribution and a sufficient number of smokers. Subjects with a previous history of a malignancy were excluded from the study. We included 1,591 serum samples from individuals aged 18 to 86 years, with a median age of 48 years. There were 801 women and 790 men. Weekly alcohol consumption was recorded for 1,583 subjects to 0 units for 853 subjects, $1-21$ units for 722 subjects, and more than 21 units for 8 subjects. Smoking status was recorded for 1,560 subjects with a daily consumption of zero cigarettes for 1,318 subjects, one to five cigarettes for 93 subjects, and more than five cigarettes for 149 subjects. Body mass index (BMI) data were provided for 1,584 subjects ranging from 16.5 to 43.2 with a median of 24.0. Of the subjects, 214 reported physical activity before sampling, 1,382 subjects reported no physical activity before sampling, and data were lacking for 5 subjects. Approval by the institutional review board is not required for studies using reference samples from non-identifiable donors obtained from external biobanks.

\section{HE4 assays}

The 1,591 serum samples were sent to us in two sets, each set randomly taken from the NOBIDA biobank. In the first set (802 samples), HE4 was measured using a manual HE4 enzyme immunoassay (EIA; Fujirebio Diagnostics AB, Gothenburg, Sweden), and in the second set (789 samples), HE4 was measured using the Architect HE4 assay (Abbott Diagnostics, Abbott Park, IL). Samples were thawed and mixed manually immediately prior to analysis. For the manual assay, two control samples, L1018 $(N=25)$, Nordic Society of Clinical Chemistry (NFKK) Reference serum X [30] $(N=25)$ were included in all runs, and three control samples $(N=14)$ provided by Fujirebio, made from serum pools, were included in some of the runs. Coefficients of variation $(\mathrm{CVs})$ for the control samples were $7.1 \%, 7.8 \%$, $8.3 \%, 11.9 \%$, and $7.4 \%$ at HE4 levels of $44.6,46.9,39.8$, 115, and 354, respectively. For the Abbott Architect assay, the CVs for the NFKK Reference serum $\mathrm{X}$ and three in house serum pools were 3.0\% $(N=9), 3.4 \%(N=6), 3.9 \%$ $(N=7)$, and $5.6 \%(N=7)$ at HE4 levels of $49.5,50.9,102$, and 309 , respectively. 
Statistical methods

For statistical calculations, we used spreadsheets (OpenOffice Calc and MS Excel) and R 2.12.1 [31] where appropriate. The influence of creatinine concentrations, age, sex, physical activity, smoking and drinking habits, and BMI was investigated prior to reference interval calculations. This was performed by log-transforming HE4, creatinine, and BMI to yield distributions closer to normality. The effect of categorical and continuous covariates was then entered into a standard multiple linear regression model.

Finally, we calculated reference intervals for the population using a previously developed script in $\mathrm{R}$ [32]. As samples were measured with two different methods, we followed the principles from International Federation of Clinical Chemistry (IFCC) [33] and Nordic Reference Interval Project (NORIP) [34] that results were first multiplied with a method-specific factor to yield comparable results. In our case, Fujirebio results were multiplied by 0.877. Reference limits are thus given in "Abbott" units. For the Fujirebio method, reference limits should thus be divided with this factor (or multiplied by 1.14).

\section{Results}

Differences between manual and automated HE4 assays

Since samples were randomly assigned to either the manual or the automated assay, we included results from both manual and automated HE4 assays in the statistical model. In a multivariate model including age, sex, creatinine concentrations, BMI, smoking, alcohol consumption, and physical activity, the manual assay was estimated to return $14.0 \%$ higher results (11.3-16.9\%), which agrees fairly well with a $12.5 \%$ difference between their medians in a univariate model.

\section{Statistical modeling of HE4 and covariates}

We first investigated the diurnal and seasonal variation by plotting HE4 results against the time of the day (not shown) and month of collection (Fig. A, Electronic supplemental materials). We did not observe any cyclical patterns by inspection. We then plotted all variables against all variables $(\ln (\mathrm{HE} 4)$, age of subjects, sex, smoking, alcohol consumption, physical activity before sampling, $\ln$ (creatinine) concentrations, and fasting/non-fasting; Fig. B, Electronic supplemental materials). The highest correlation for $\ln (\mathrm{HE} 4)$ was seen between $\ln (\mathrm{HE} 4)$ and age $(0.60)$. The relation between $\ln (\mathrm{HE} 4)$ and age was not a straight line, implying that age must be modeled by a higher degree polynomial. Other strong correlations were seen between $\ln$ (creatinine) and sex.

We then entered data into a multivariate model, comprising $\ln$ (HE4), age of subjects, sex, smoking, alcohol consumption, physical activity before sampling, $\ln$ (creatinine) concentrations, and fasting/non-fasting. For model selection, we used the Akaike Information Criterion (AICc) [35]. Modeling age with a second-degree polynomial (e.g., $\left.\mathrm{Age}^{\wedge} 2\right)$ returned a lower AICc ( -71.9 versus 0.4$)$, and we thus chose the model including the second-degree polynomial. Table A (Electronic supplement material) summarizes the statistical model chosen.

HE4 and age

HE4 increases with increasing age, with increasing slope. In the multivariate model, detailed above, this corresponds to $2 \%$ higher HE4 levels at 30 years of age (compared to 20 years of age), $9 \%$ at 40 years, $20 \%$ at 50 years, $37 \%$ at 60 years, $63 \%$ at 70 years, and $101 \%$ at 80 years of age.

\section{HE4 and smoking}

In the multivariate model, HE4 is $29 \%$ higher in smokers than in nonsmokers. From inspection (Fig. 1), one may suspect that there is a combination of age and smoking which might be statistically significant in a larger material consisting of more smokers. This combination may describe that in younger patients having a low baseline HE4, smoking gives a larger increase of HE4 than in older patients, where the baseline HE4 is higher.

\section{HE4 and sex}

The difference between sexes is relatively small, albeit it is strongly statistically significant. Male sex is associated with $7 \%$ lower HE4 levels. However, the age-related increase in HE4 is more pronounced in men (Figs. 2 and 3), so young men will have lower HE4 than young women, but elderly men will have higher HE4 than elderly women.

\section{HE4 and BMI}

High BMI is associated with lower HE4 levels, corresponding to $5 \%$ lower HE4 at BMI of 25 (compared to 20 ) and $10 \%$ lower at BMI of 30 .

HE4 and creatinine

High HE4 levels are associated with higher creatinine levels, if creatinine at $50 \mathrm{nmol} / \mathrm{L}$ is considered baseline, creatinine at $60 \mathrm{nmol} / \mathrm{L}$ is associated with $6 \%$ higher HE4 levels, $70 \mathrm{nmol} / \mathrm{L}$ with $12 \%$ higher levels, $80 \mathrm{nmol} / \mathrm{L}$ with 
Fig. 1 Co-plot of HE4 and age for smokers and nonsmokers. Smokers notably have higher HE4 levels but also a larger spread (standard deviation)

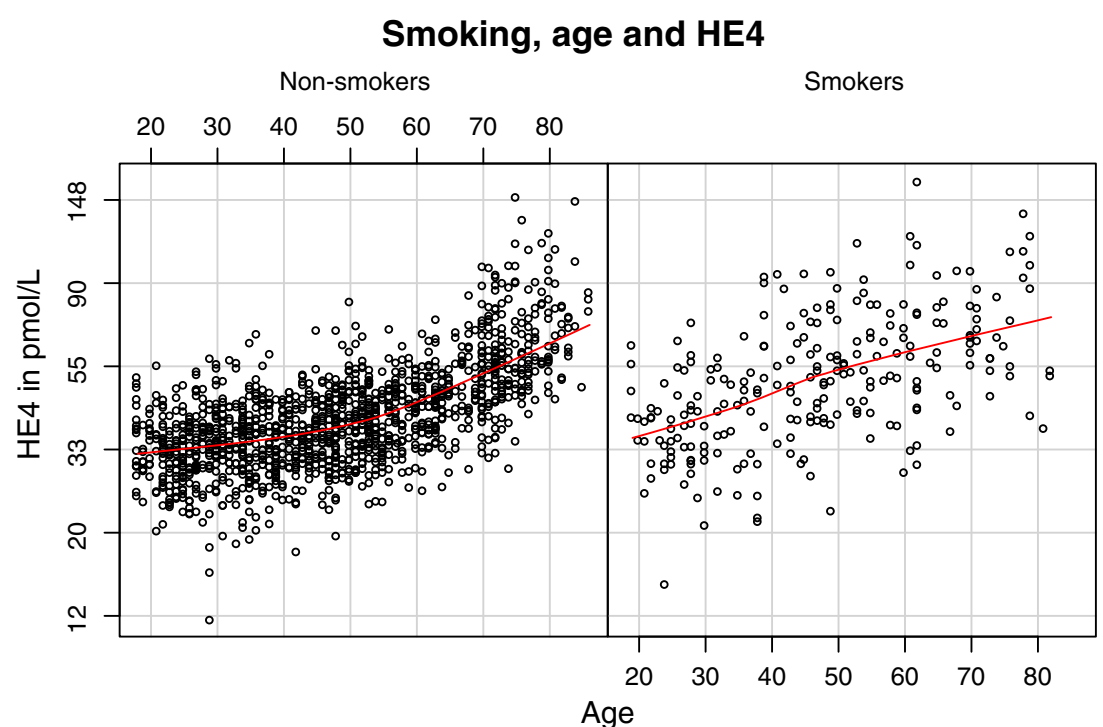

$17 \%$ higher levels, $90 \mathrm{nmol} / \mathrm{L}$ with $22 \%$ higher levels, and $100 \mathrm{nmol} / \mathrm{L}$ with $27 \%$ higher levels.

Proposed reference limits for HE4

Calculating reference limits for HE4 is demanding, with its many covariates/determinants. We chose this approach: We first adjusted results to Abbott Architect levels, excluded subjects with active smoking, and entered results into a script, previously developed by us [32]. We treated men and female separately, mainly because there is presently little use of the HE4 assay for male subjects. In calculating reference intervals, we followed the recommendations from IFCC and NORIP by removing outliers from the calculation of reference intervals by a parametric method. Outliers were removed by applying "Tukey's fence" [36]. In this context, subjects having a result (after results were transformed to a Gaussian distribution) more than 1.5 times the interquartile range (the
Fig. 2 Graph of reference limits ( 97.5 percentile with $90 \%$ confidence limits) for HE4 in non-smoking women. Age is here modeled by fractional polynomials and HE4 by an exponential-normal transformation. HE4 increases steeply with increasing age
HE4 in non-smoking women

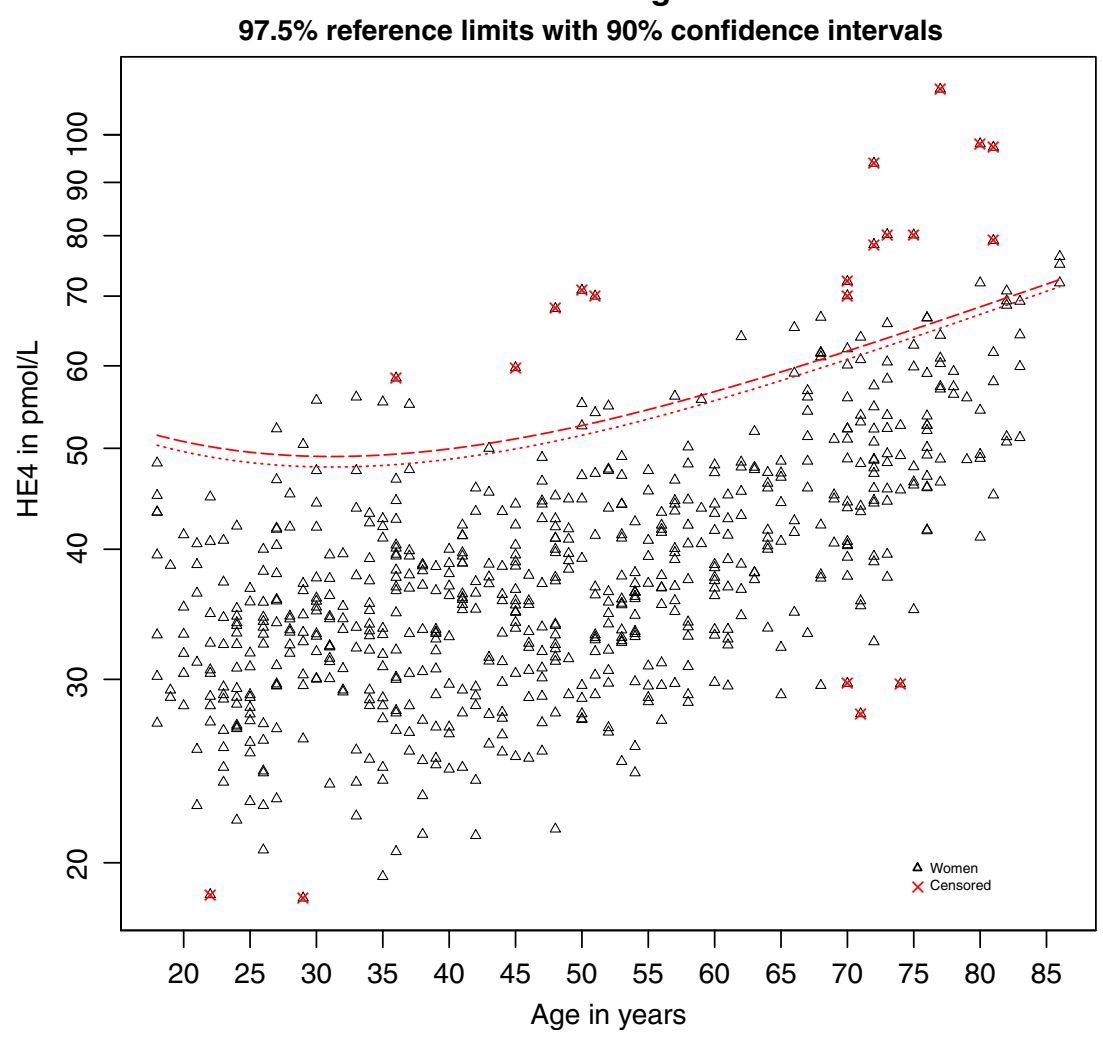


Fig. 3 Graph of reference limits (97.5 percentile with $90 \%$ confidence limits) for HE4 in non-smoking men. Age is here modeled by fractional polynomials and HE4 by an exponential-normal transformation. HE4 increases steeply with increasing age

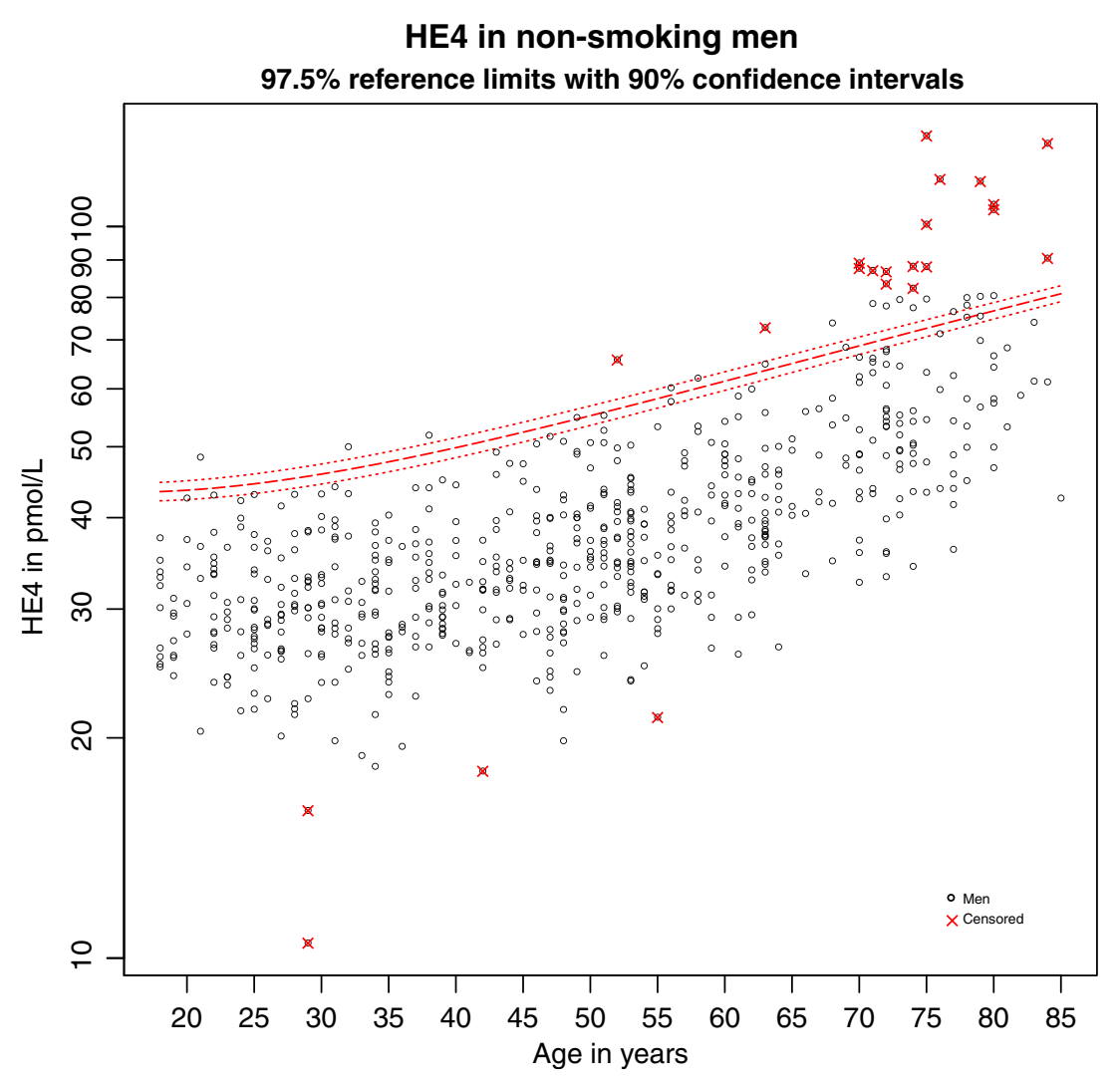

difference between the 75th and 25th percentiles) outside the 25 th or 75 th percentile were excluded from calculations.

The proposed upper reference limits for women and men are plotted together with the observations in Figs. 2 and 3, respectively. HE4 increases steeply with increasing age. In the elderly $(70+)$, there is a relatively large subgroup of individuals with high HE4 outside the distribution. The detailed reference limits for both sexes are given in Table 1 .

\section{Discussion}

HE4 levels in normal subjects

Although HE4 is a human epididymis protein, and proposed as a marker of ovarian cancer, differences between sexes are small, suggestive that the main source of HE4 in healthy individuals may not be related to the reproductive organs. We did not look for patterns attributable to the female menstrual cycle, but given the rather small residual variance in the study and relatively low HE4 levels in younger women, such a factor must be small. A recent publication in Tumor Biology describes a modest, but potentially important, variation in HE4 levels between the different phases of the female menstrual cycle [37]. HE4 levels seem not to be affected by time of sampling, fasting, exercise, or seasonal factors.
We have identified two main determinants of HE4 levels in healthy individuals. The first determinant is smoking, and particularly in younger subjects, active smoking is related to a clear increase in HE4 levels. We have previously noted an increase in carcinoembryonic antigen (CEA) levels and a decrease in NSE levels in active smokers [38]. The mechanism behind elevated HE4 levels in smokers is somewhat unclear. For the similar increase in CEA levels, CEA is expressed in airway epithelium and airway inflammation is likely to explain, or at least contribute to, the elevated levels observed in smokers [39]. As HE4 is also expressed in airway epithelium [16], inflammation might contribute to the elevated serum levels of HE4 in active smokers, but this remains speculative until further studies pinpoint the association between smoking and HE4.

The second determinant is associated with age. We see a large increase of HE4 levels in the elderly subjects. Creatinine levels and BMI are also statistically significant, but both creatinine levels and BMI are also significantly associated with the age of subjects, which should warrant caution in the interpretation. Further, the interaction between active smoking and age is not clear-cut. We see a tendency of a larger smoking-related increase in younger subjects, but the absolute number of smokers is too small to allow more extensive mathematical modeling.

We note that our proposed reference limits are markedly lower in all age groups than the reference limit proposed in 
Table 1 Suggested age-dependent reference limits for HE4 (picomoles per liter)
Reference limits for HE4 (picomoles per liter) in men and women are given as 97.5 percentiles with $90 \%$ confidence intervals. Age-dependent limits were calculated from results obtained with the automated method on the Abbott Architect platform. Smokers were excluded prior to calculation

\begin{tabular}{|c|c|c|c|c|c|c|}
\hline \multirow{3}{*}{$\frac{\text { Age }}{18}$} & \multicolumn{3}{|l|}{ Men } & \multicolumn{3}{|l|}{ Women } \\
\hline & \multirow{2}{*}{$\frac{\text { Reference limit }}{43.4}$} & \multicolumn{2}{|c|}{ Confidence interval } & \multirow{2}{*}{$\frac{\text { Reference limit }}{51.5}$} & \multicolumn{2}{|c|}{ Confidence interval } \\
\hline & & 42.2 & 44.7 & & 50.3 & 52.6 \\
\hline 22 & 43.9 & 42.6 & 45.2 & 50.2 & 49.1 & 51.3 \\
\hline 26 & 44.7 & 43.4 & 46.1 & 49.4 & 48.3 & 50.6 \\
\hline 30 & 45.9 & 44.5 & 47.4 & 49.1 & 48.0 & 50.3 \\
\hline 34 & 47.3 & 45.8 & 48.8 & 49.2 & 48.1 & 50.3 \\
\hline 38 & 48.9 & 47.4 & 50.5 & 49.6 & 48.5 & 50.8 \\
\hline 42 & 50.8 & 49.2 & 52.4 & 50.3 & 49.2 & 51.5 \\
\hline 46 & 52.9 & 51.3 & 54.6 & 51.3 & 50.2 & 52.5 \\
\hline 50 & 55.1 & 53.5 & 56.9 & 52.6 & 51.5 & 53.7 \\
\hline 54 & 57.5 & 55.9 & 59.3 & 54.1 & 52.9 & 55.2 \\
\hline 58 & 60.1 & 58.4 & 61.9 & 55.8 & 54.6 & 56.9 \\
\hline 62 & 62.8 & 61.1 & 64.7 & 57.7 & 56.5 & 58.8 \\
\hline 66 & 65.7 & 63.9 & 67.6 & 59.7 & 58.6 & 60.9 \\
\hline 70 & 68.7 & 66.8 & 70.6 & 62.0 & 60.9 & 63.2 \\
\hline 74 & 71.8 & 69.9 & 73.8 & 64.4 & 63.3 & 65.6 \\
\hline 78 & 75.0 & 73.1 & 77.0 & 67.0 & 65.9 & 68.2 \\
\hline 82 & 78.4 & 76.4 & 80.4 & 69.7 & 68.6 & 70.9 \\
\hline 86 & & & & 72.6 & 71.5 & 73.8 \\
\hline
\end{tabular}

the HE4 EIA kit insert $(\sim 150 \mathrm{pmol} / \mathrm{L}$ for pre- and postmenopausal women). Had we included smokers prior to calculating reference limits, the contrast to the limits suggested in the kit insert would be less dramatic. The remaining difference could possibly be explained by differences in size and donor characteristics of the study populations, but this remains speculative. Our reference limits are also markedly lower than the 95 percentiles of the control groups in a recent publication by Molina et al. [40] of $138 \mathrm{pmol} / \mathrm{L}$ (34 premenopausal women) and $132 \mathrm{pmol} / \mathrm{L}$ (32 postmenopausal women), respectively. However, the small size of the groups and the lack of (healthy) donor characteristics make comparisons difficult. The fact that the 95 percentile among premenopausal women with benign gynecological diseases in the Molina study is markedly lower than in the group of healthy premenopausal controls (77.6 pmol/L vs $138.3 \mathrm{pmol} / \mathrm{L}$, respectively) suggests that the control group might not be representative of healthy women. In this respect, the 95 percentile among healthy women $(N=109)$ in the study by Lenhard et al. [41] are more comparable to our reference limits. For the age groups where comparisons are possible (below 65 years), our limits are also comparable to the reference limit suggested in the large study by Park et al. [29]. Interestingly, given the large size of both study groups, the tendency of increasing HE4 levels with increasing age seen in our study population was not found in the Korean women. Although we have no explanation for this discrepancy, it serves as a reminder that different populations (in this case Nordic vs Korean) can display varying biology, both in sickness and in health. It is quite possible that an eventual (i.e., in higher age groups) increase in HE4 levels with increasing age also had been identified in the Korean women had donors above 65 years been included.

Elevated HE4 levels have been observed in patients with renal failure [42], suggesting that HE4 (like many tumor markers) is cleared from the circulation principally through glomerular filtration. However, we do not know if the reductions in glomerular filtration rate (GFR) often associated with increasing age can explain the elevated HE4 levels seen in elderly subjects in our study. This hypothetical, but perhaps likely explanation is difficult to validate since the only marker for renal function in our data, creatinine, is rarely elevated in the early stages of kidney disease. This is particularly true in patients with reduced muscle mass, a common characteristic of elderly patients.

\section{Lessons for cancer testing}

There are probably two important lessons. First, any effective algorithm for detecting cancer involving HE4 levels should include age of subjects. The relation between age and HE4 is clearly not straight, and probably age must be modeled with a polynomial of higher degree. A practical consequence of our findings may be the reassessment of previous studies. Since HE4 increases with increasing age, and cancer risk also increases with increasing age, HE4 will, in studies where age is not included, be a pseudo- 
marker for age, and the elevated HE4 levels in cancer subjects might thus be related more to their higher age than to their tumors. HE4 here behaves differently from CA125. When we made a similar study for CA125, only minor changes in CA125 levels could be attributed to the age of subjects [38].

Lesson two is related to smoking. Smokers have higher levels and a larger standard deviation (spread). The proportion of smokers in the study is low, but the study clearly suggests that HE4 levels in smokers differ from nonsmokers. A conservative approach is thus to exclude smoking subjects when calculating and using diagnostic indices for HE4. One should consider separate indices for smokers; however, one must then first pinpoint the relationship between the cigarette consumption and HE4 levels.

For future studies, we would like to evaluate the effect of age and smoking status on the performance of the ROMA in a clinical setting. Additionally, it could be informative to clarify the relationship between HE4 levels and early stage renal failure. We suggest that HE4 could be measured in a patient population where GFR has been determined by inulin clearance, still considered the gold standard, or novel methods using radiotracers $\left({ }^{51} \mathrm{Cr}\right.$-EDTA $)$ or contrast agents (Iohexol). Knowledge of this relationship might be particularly important in a situation where HE4 is used in the follow-up of cancer patients. The potential for confusion is significant if subclinical decreases in GFR, as is often observed with chemotherapy or increasing age, could in itself lead to rising HE4 levels normally indicative of treatment failure, progression or relapse of a malignant disease.

Acknowledgments The authors would like to thank Laila Gjerdalen for technical assistance, the Nordic Society of Clinical Chemistry (NFKK) and the Nordic Reference Interval Project Biobank and Database (NOBIDA) for making samples and data available for this project. All assay kits were provided free of charge from Fujirebio Diagnostics AB and Abbott Diagnostics.

\section{Conflicts of interest None}

Open Access This article is distributed under the terms of the Creative Commons Attribution Noncommercial License which permits any noncommercial use, distribution, and reproduction in any medium, provided the original author(s) and source are credited.

\section{References}

1. Curtin JP. Management of the adnexal mass. Gynecol Oncol. 1994;55:S42-6.

2. Sankaranarayanan R, Ferlay J. Worldwide burden of gynaecological cancer: the size of the problem. Best Pract Res Clin Obstet Gynaecol. 2006;20:207-25.

3. Earle CC, Schrag D, Neville BA, Yabroff KR, Topor M, Fahey A, et al. Effect of surgeon specialty on processes of care and outcomes for ovarian cancer patients. J Natl Cancer Inst. 2006;98:172-80.

4. Engelen MJ, Kos HE, Willemse PH, Aalders JG, de Vries EG, Schaapveld M, et al. Surgery by consultant gynecologic oncologists improves survival in patients with ovarian carcinoma. Cancer. 2006;106:589-98.

5. Giede KC, Kieser K, Dodge J, Rosen B. Who should operate on patients with ovarian cancer? An evidence-based review. Gynecol Oncol. 2005;99:447-61.

6. Paulsen T, Kjaerheim K, Kaern J, Tretli S, Trope C. Improved short-term survival for advanced ovarian, tubal, and peritoneal cancer patients operated at teaching hospitals. Int $\mathrm{J}$ Gynecol Cancer. 2006;16 Suppl 1:11-7.

7. Tingulstad S, Skjeldestad FE, Hagen B. The effect of centralization of primary surgery on survival in ovarian cancer patients. Obstet Gynecol. 2003;102:499-505.

8. Bast Jr RC, Feeney M, Lazarus H, Nadler LM, Colvin RB, Knapp RC. Reactivity of a monoclonal antibody with human ovarian carcinoma. J Clin Invest. 1981;68:1331-7.

9. Bast Jr RC, Klug TL, St JE, Jenison E, Niloff JM, Lazarus H, et al. A radioimmunoassay using a monoclonal antibody to monitor the course of epithelial ovarian cancer. N Engl J Med. 1983;309:883-7.

10. Jacobs I, Oram D, Fairbanks J, Turner J, Frost C, Grudzinskas JG. A risk of malignancy index incorporating CA 125, ultrasound and menopausal status for the accurate preoperative diagnosis of ovarian cancer. Br J Obstet Gynaecol. 1990;97:922-9.

11. Tingulstad S, Hagen B, Skjeldestad FE, Onsrud M, Kiserud T, Halvorsen T, et al. Evaluation of a risk of malignancy index based on serum CA125, ultrasound findings and menopausal status in the pre-operative diagnosis of pelvic masses. $\mathrm{Br} \mathrm{J}$ Obstet Gynaecol. 1996;103:826-31.

12. Terry KL, Sluss PM, Skates SJ, Mok SC, Ye B, Vitonis AF, et al. Blood and urine markers for ovarian cancer: a comprehensive review. Dis Markers. 2004;20:53-70.

13. Carlson KJ, Skates SJ, Singer DE. Screening for ovarian cancer. Ann Intern Med. 1994;121:124-32.

14. Markman M. The role of CA-125 in the management of ovarian cancer. Oncologist. 1997;2:6-9.

15. Diamandis EP. Cancer biomarkers: can we turn recent failures into success? J Natl Cancer Inst. 2010;102:1462-7.

16. Galgano MT, Hampton GM, Frierson Jr HF. Comprehensive analysis of HE4 expression in normal and malignant human tissues. Mod Pathol. 2006;19:847-53.

17. Hellstrom I, Raycraft J, Hayden-Ledbetter M, Ledbetter JA, Schummer M, McIntosh M, et al. The HE4 (WFDC2) protein is a biomarker for ovarian carcinoma. Cancer Res. 2003;63:3695-700.

18. Lu KH, Patterson AP, Wang L, Marquez RT, Atkinson EN, Baggerly KA, et al. Selection of potential markers for epithelial ovarian cancer with gene expression arrays and recursive descent partition analysis. Clin Cancer Res. 2004;10:3291-300.

19. Schummer M, Ng WV, Bumgarner RE, Nelson PS, Schummer B, Bednarski DW, et al. Comparative hybridization of an array of 21,500 ovarian cDNAs for the discovery of genes overexpressed in ovarian carcinomas. Gene. 1999;238:375-85.

20. Moore RG, Brown AK, Miller MC, Skates S, Allard WJ, Verch T, et al. The use of multiple novel tumor biomarkers for the detection of ovarian carcinoma in patients with a pelvic mass. Gynecol Oncol. 2008;108:402-8.

21. Moore RG, McMeekin DS, Brown AK, DiSilvestro P, Miller MC, Allard WJ, et al. A novel multiple marker bioassay utilizing HE4 and CA125 for the prediction of ovarian cancer in patients with a pelvic mass. Gynecol Oncol. 2009;112:40-6.

22. Moore RG, Jabre-Raughley M, Brown AK, Robison KM, Miller $\mathrm{MC}$, Allard WJ, et al. Comparison of a novel multiple marker assay vs the Risk of Malignancy Index for the prediction of 
epithelial ovarian cancer in patients with a pelvic mass. Am J Obstet Gynecol. 2010;203:228.e1-6.

23. Jacob F, Meier M, Caduff R, Goldstein D, Pochechueva T, Hacker $\mathrm{N}$, et al. No benefit from combining HE4 and CA125 as ovarian tumor markers in a clinical setting. Gynecol Oncol. 2011;121 (3):487-91.

24. Montagnana M, Danese E, Ruzzenente O, Bresciani V, Nuzzo T, Gelati M, et al. The ROMA (Risk of Ovarian Malignancy Algorithm) for estimating the risk of epithelial ovarian cancer in women presenting with pelvic mass: is it really useful? Clin Chem Lab Med. 2011;49:521-5.

25. Kamei M, Yamashita S, Tokuishi K, Hashioto T, Moroga T, Suehiro S, et al. HE4 expression can be associated with lymph node metastases and disease-free survival in breast cancer. Anticancer Res. 2010;30:4779-83.

26. Moore RG, Brown AK, Miller MC, Badgwell D, Lu Z, Allard WJ, et al. Utility of a novel serum tumor biomarker HE4 in patients with endometrioid adenocarcinoma of the uterus. Gynecol Oncol. 2008;110:196-201.

27. Yamashita S, Tokuishi K, Hashimoto T, Moroga T, Kamei M, Ono $\mathrm{K}$, et al. Prognostic significance of HE4 expression in pulmonary adenocarcinoma. Tumour Biol. 2011;32:265-71.

28. Huhtinen K, Suvitie P, Hiissa J, Junnila J, Huvila J, Kujari H, et al. Serum HE4 concentration differentiates malignant ovarian tumours from ovarian endometriotic cysts. Br J Cancer. 2009;100:1315-9.

29. Park Y, Kim Y, Lee EY, Lee JH, Kim HS. Reference ranges for HE4 and CA125 in a large Asian population by automated assays and diagnostic performances for ovarian cancer. Int $\mathrm{J}$ Cancer. 2011. doi:10.1002/ijc.26129.

30. Rustad P, Simonsson P, Felding P, Pedersen M. Nordic Reference Interval Project Bio-bank and Database (NOBIDA): a source for future estimation and retrospective evaluation of reference intervals. Scand J Clin Lab Invest. 2004;64:431-8.

31. R Development Core Team. R: A Language and Environment for Statistical Computing. [R 2.12.1]. 2011. Vienna, Austria, R Foundation for Statistical Computing, http://www.R-project.org. Ref Type: Computer Program. Accessed 25 Feb 2011.

32. Bjerner J. Age-dependent biochemical quantities: an approach for calculating reference intervals. Scand J Clin Lab Invest. 2007;67:707-22.
33. Solberg HE. The IFCC recommendation on estimation of reference intervals. The RefVal program. Clin Chem Lab Med. 2004;42:710-4.

34. Rustad P, Felding P, Lahti A, Hyltoft PP. Descriptive analytical data and consequences for calculation of common reference intervals in the Nordic Reference Interval Project 2000. Scand J Clin Lab Invest. 2004;64:343-70.

35. Akaike H. A new look at statistical model identification. IEEE Trans Autom Control. 1974;19:716-23.

36. Tukey J. Exploratory data analysis. Reading: Addison-Wesley; 1977.

37. Anastasi E, Granato T, Marchei GG, Viggiani V, Colaprisca B, Comploj S, et al. Ovarian tumor marker HE4 is differently expressed during the phases of the menstrual cycle in healthy young women. Tumour Biol. 2010;31:411-5.

38. Bjerner J, Hogetveit A, Wold AK, Vangsnes K, Paus E, Bjoro T, et al. Reference intervals for carcinoembryonic antigen (CEA), CA125, MUC1, Alfa-foeto-protein (AFP), neuron-specific enolase (NSE) and CA19.9 from the NORIP study. Scand J Clin Lab Invest. 2008;68:703-13.

39. Stockley RA, Shaw J, Whitfield AG, Whitehead TP, Clarke CA, Burnett D. Effect of cigarette smoking, pulmonary inflammation, and lung disease on concentrations of carcinoembryonic antigen in serum and secretions. Thorax. 1986;41:17-24.

40. Molina R, Escudero JM, Auge JM, Filella X, Foj L, Torne A, et al. HE4 a novel tumour marker for ovarian cancer: comparison with CA 125 and ROMA algorithm in patients with gynaecological diseases. Tumour Biol. 2011;32(6):1087-95.

41. Lenhard M, Stieber P, Hertlein L, Kirschenhofer A, Fürst S, Mayr D, Nagel D, Hofmann K, Krocker K, Burges A. The diagnostic accuracy of two human epididymis protein 4 (HE4) testing systems in combination with CA125 in the differential diagnosis of ovarian masses. Clin Chem Lab Med. 2011 [Epub ahead of print].

42. Park Y, Lee JH, Hong DJ, Lee EY, Kim HS. Diagnostic performances of HE4 and CA125 for the detection of ovarian cancer from patients with various gynecologic and non-gynecologic diseases. Clin Biochem. 2011;44(1011):884-8. 